\title{
IMPACTS OF CLIMATE CHANGE ON EU AGRICULTURE
}

\author{
Shailesh Shrestha ${ }^{1,2}$, Pavel Ciaian $*^{2}$, Mihaly Himics ${ }^{2,3}$, Benjamin Van Doorslaer ${ }^{2}$
}

\author{
Address: \\ ${ }^{1}$ Scotland's Rural College, Land Economy and Environment, King's Buildings, West Mains Road, Edinburgh EH9 3JG, UK, phone: +131 535 4099 \\ ${ }^{2}$ European Commission, DG JRC, C/ Inca Garcilaso 3, 41092 Seville, Spain, phone: +34 954488429 \\ ${ }^{3}$ University of Bonn, Institute for Food and Resource Economics, Nussallee 21 D- 53115 Bonn, Germany, phone: +49 228732335 \\ *Corresponding author: pavel.ciaian@ec.europa.eu
}

\begin{abstract}
The current paper investigates the medium term economic impact of climate changes on the EU agriculture. The yield change data under climate change scenarios are taken from the BIOMA (Biophysical Models Application) simulation environment. We employ CAPRI modelling framework to identify the EU aggregate economic effects as well as regional impacts. We take into account supply and market price adjustments of the EU agricultural sector as well as technical adaptation of crops to climate change. Overall results indicate an increase in yields and production level in the EU agricultural sector due to the climate change. In general, there are relatively small effects at the EU aggregate. For example, the value of land use and welfare change by approximately between $-2 \%$ and $0.2 \%$. However, there is a stronger impact at regional level with some stronger effects prevailing particularly in the Central and Northern EU and smaller impacts are observed in Southern Europe. Regional impacts of climate change vary by a factor higher up to 10 relative to the aggregate EU impacts. The price adjustments reduce the response of agricultural sector to climate change in particular with respect to production and income changes. The technical adaption of crops to climate change may result in a change production and land use by a factor between 1.4 and 6 relative to no-adaptation situation.
\end{abstract}

Keywords: climate change, agricultural productivity, adaptation, Europe

JEL: Q11, Q15, O13

\section{INTRODUCTION}

With a growing concern of changing global temperature and precipitation patterns, an extensive list of studies have been conducted to examine the impact of climate changes on agricultural production and farming sector (Easterling et al. 1993; Chang 2002; Peiris et al. 1996; Hakala, 1998; Brown and Rosenberg, 1999; Rotter and Van de Geijn, 1999; Craigon et al. 2002; Jones and Thornton 2003). Many studies have concluded that the effects of climate change on crop yields would highly depend upon the geographical location of the crop production with crops in some regions benefited (Cuculeanu, Marcia and Simota 1999; Ghaffari, Cook and Lee 2002) while crops in other regions showed adverse effect under new climatic conditions (Woodward, Thompson and Mckee 1991; Wheeler et al. 1996; Batts et al. 1997; Morison and Lawlor 1999; Jones and Thornton 2003; Parry et al. 2004). An increase in spring/summer air temperatures would be beneficial to crop production at northern temperate latitude sites where the length of growing season would increase. By contrast, warmer temperatures during crop development could depress yields in those regions where summer temperature and water are already limiting (Rosenzweig and Tubiello 1997).

There are a growing number of studies in recent years on determining the effects of climate change on EU agriculture (e.g. Reidsma, Ewert and Lansink 2007;
Ciscar 2009). Studies indicate a strong regional divergence in climate change effects in EU. In northern areas climate change may produce positive effects on agriculture through introduction of new crop varieties, higher yields and expansion of suitable areas for crop cultivation. In southern areas the disadvantages will likely predominate. The expected increase in water shortage and extreme weather events may cause lower harvestable yields, higher yield variability and a reduction in suitable areas for cultivation (Olesen and Bindi 2002; Olesen 2008; Iglesias et al. 2009). Most of the studies focus on biophysical and environmental consequences of climate change (Bazzaz and Sombroek 1996; Gornall et al. 2010). Few studies analyse the EU wide economic impacts at regional level. The literature in the field of climate change effects mainly focuses on the impacts in small restricted geographical areas or in selected regions (e.g. Brereton and O'Riordan 2001; Sweeney et. al. 2003; Holden et al. 2004; Holden, Brereton and Fitzgerald 2008; Walker and Schulze 2008; Quiroga and Iglesias 2009) or global market impacts (e.g. Darwin et al. 1995; Parry et al. 2004).

The objective of this paper is to analyse the economic impacts of climate change and to examine the adaptation measures in EU agriculture. The CAPRI, an agricultural partial equilibrium model was used for this paper. The yield change data under climate change are taken from the BIOMA (Biophysical Models Application) simulation environment. 
The results in this paper are subject, however, to some limitations. In particular we do not take into account full adaptation of the EU agricultural sector to climate changes. We investigate the medium term effect of climate change on the EU agriculture. A long term adjustment may mitigate some of the effects and the sectoral and/or regional impacts maybe different than our results indicate. The climate change scenarios are introduced only for the European countries and crop yields are assumed to be unchanged in the non-EU countries. Finally, the use of stylized template supply modules in CAPRI which are structurally identical and express differences between regions solely by parameters alone might fall short of capturing the full regional diversity of farming systems in the EU and their response to climate change. However, the current structure of the approach gives a good balance between increased detail of represented regions and robustness of the model results for medium term horizon economic analysis of climate changes.

\section{METHODOLOGY}

\section{CAPRI}

The Common Agricultural Regionalised Impact Analysis model (CAPRI) is a global, spatial, partial equilibrium model with a focus on Europe specifically designed to analyse CAP measures and trade policies for agricultural products (Britz and Witzke 2008). CAPRI consists of two modules, the highly detailed and disaggregated supply module for Europe and the global market module, which are linked by sequential calibration such that production, demand, trade and prices can be simulated simultaneously and interactively from global to regional and farm-type scale.

The agricultural supply module consists of nonlinear programming models for EU27, the Western Balkans, Norway and Turkey, which depict farming decisions in detail at the NUTS-2 level or at the level of farm types. The mathematical programming approach offers a high degree of flexibility in capturing important interactions between production activities and with the environment as well as in modelling CAP and national policy measures. The programming models comprise low- and high-intensive variants for most crop and livestock activities while a non-linear cost function captures the effects of capital and labour on the farm behaviour.

The market module is a static, deterministic, partial, spatial model with global coverage, depicting about 50 commodities (primary and secondary agricultural products) and breaking the world down into 60 countries or country blocks, grouped into 30 trade blocks. Its spatial specification allows bilateral trade flows and policies between trade blocks in the model to be modelled. Within each trade block, the current version assumes perfect markets (for both primary and secondary products) so that prices for all countries move together within a market block. The parameters of the secondorder flexible behavioural functions for supply, feed demand, of major processing industries and final demand are based on elasticities taken from other studies and modelling systems, and calibrated to projected quantities and prices in the simulation year, while observing required theoretical properties from micro-economics.

Apart from the rich detail on the supply side of the model, CAPRI's strengths are that it simulates results for the EU at sub-member state (NUTS-2) level, whilst at the same time being able to model consistently global world agricultural trade, with the EU's most important trade partners separately identified and bilateral trade flows between them and the EU accounted for. It also comprises a consistent welfare analysis, a detailed analysis of agricultural policies.

CAPRI has been used in numerous assessments of agricultural and trade policies and environmental effects, such as GHG emissions from the agricultural sector, the impacts of direct payments schemes, the quota milk abolition, biofuel policies or bilateral trade policies (e.g. Gocht et al. 2013; Blanco-Fonseca et al. 2010; Leip et al. 2010).

\section{Modelling climate change}

A number of economic approaches and models are applied for assessing the economic impacts of climate change. They can be classified as either 'structural' or 'spatial-analogue' approaches. The first approach is interdisciplinary and interlinks models from several

Table 1 Adaptation measures considered in BIOMA model for different crops

\begin{tabular}{|c|c|c|c|}
\hline Crop & Growth cycle length & Sowing date & Irrigation \\
\hline Wheat & $\begin{array}{l}3 \text { levels: shorter }(-10 \mathrm{~d}) \text {, } \\
\text { longer }(+10 \mathrm{~d}) \text { maturity } \\
\text { and standard (no change) }\end{array}$ & $\begin{array}{l}3 \text { levels: delay of } 10 \mathrm{~d} \text {, } \\
\text { delay of } 20 \mathrm{~d} \text { and no } \\
\text { delay }\end{array}$ & No \\
\hline Rapeseed & $\begin{array}{l}3 \text { levels: shorter }(-10 \mathrm{~d}) \text {, } \\
\text { longer }(+10 \mathrm{~d}) \text { maturity } \\
\text { and standard (no change) }\end{array}$ & $\begin{array}{l}3 \text { levels: delay of } 10 \mathrm{~d} \text {, } \\
\text { delay of } 20 \mathrm{~d} \text { and no } \\
\text { delay }\end{array}$ & No \\
\hline Sunflower & $\begin{array}{l}3 \text { levels: shorter }(-10 \mathrm{~d}) \text {, } \\
\text { longer }(+10 \mathrm{~d}) \text { maturity } \\
\text { and standard (no change) }\end{array}$ & $\begin{array}{l}3 \text { levels: anticipation of } \\
10 \mathrm{~d} \text {, anticipation of } 20 \mathrm{~d} \\
\text { and no anticipation }\end{array}$ & No \\
\hline Maize & $\begin{array}{l}3 \text { levels: shorter }(-10 \mathrm{~d}) \text {, } \\
\text { longer }(+10 \mathrm{~d}) \text { maturity } \\
\text { and standard (no change) }\end{array}$ & $\begin{array}{l}3 \text { levels: anticipation of } \\
10 \mathrm{~d} \text {, anticipation of } 20 \mathrm{~d} \\
\text { and no anticipation }\end{array}$ & $\begin{array}{l}\text { Yes, up to } 6 \text { irrigation for } \\
\text { a total of } 2700 \mathrm{~m}^{3} \mathrm{ha}^{-1}\end{array}$ \\
\hline
\end{tabular}


disciplines (Schimmelpfennig et al. 1996; Adams et al. 1998a). A common method applied to interlink different type of models consists of using biophysical models to predict crop yield effects of climate change scenarios which are then used as an input into the economic model to predict economic impacts (e.g. Adams et al. 1998b). The key distinguishing feature of the 'spatial-analogue' approach is that it is more explicit in taking into consideration spatial variation in climate change (e.g. Darwin et al. 1995). In our paper we apply the first approach. The advantage of this approach is that it provides a more explicit representation of causal effects and adjustments of the agricultural sector to climate change.

In agricultural production, one of the major impacts of climate change is manifested through a change in crop and grass yields. The supply module of CAPRI has a capability to examine the effects of these changes in yields of different crops and grass and provides an economic analysis on EU agricultural sector. Although CAPRI does not have a facility for a direct use of climate parameters within the model, changes in crop and grass yields under different climate change scenarios can be used in CAPRI to analyse the economic impacts of climate change. The model currently uses 2004 as a base year (averaged data for 2003, 2004 and 2005) and projects a baseline scenario to 2020. Hence the model is capable to assess the impacts of climate change for the year 2020 and to do this the model requires input data for different crops and grass yields under climate scenarios for the year 2020 based on assumed changes in temperature and rainfall across the EU. The model then adjusts those yields based on the profitability of a particular crop under a set of resource constraints (such as land and nutrient balances).

The yield change data under climate change scenarios are taken from the BIOMA biophysical modelling platform (Confalonieri et al. 2009; Stöckle, Donatelli and Nelson 2003). BIOMA is a modular software platform which integrates the following set of biophysical models for different crops: the generic crop simulators CropSyst (Cropping Systems Simulator) and WOFOST (World Food Studies), the rice model WARM (Water Accounting Rice Model), and a modelling solution for the simulation of cropping systems STICS (Simulateur Multidisciplinaire pour les Cultures Standard). CropSyst is a multi-year, multi-crop, daily time step cropping systems model and simulates the soil water budget, soil-plant nitrogen budget, crop phenology, canopy and root growth, biomass production, crop yield, residue production and decomposition, soil erosion by water, and salinity (Stöckle, Donatelli and Nelson 2003). WOFOST simulates crop development from emergence until harvest for different annual crops such as wheat, sunflower, maize, and rapeseed through the calibration of crop-specific parameters. The model is composed of three main blocks: weather, crop growth and soil water balance. Weather comprises the main input for crop growth: gases, radiation, temperature and water. Crop growth simulates the main processes (transpiration and assimilation) of crop development, whereas soil water balance is an interface between weather and crop growth components determining the amount of water from rainfall available for the plant as a proxy to estimate water limited growth rates from potential (Supit, Hooijer and Van Diepen 1994). WARM is a crop growth model specific for paddy rice simulations. It aims at accounting for all the main processes characterizing the typical features of the rice system (e.g. diseases management, abiotic stresses and nutrient cycles). WARM simulates rice growth taking into account micrometeorological peculiarities of paddy fields, diseases, hydrology of paddy soils, temperatureshock induced spikelet sterility and reproduces these biophysical processes with a consistent level of complexity. STICS simulates yields and variables related to the crop in term of quantity and quality and variables related to the soil-crop system, particularly water balance and nitrogen balance. Overall the key drivers through which climate change impacts crop yields in BIOMA include changes in temperature levels, rainfalls and changes in carbon dioxide (CO2) and its fertilization on crops. ${ }^{1}$

Changes in crop yields are reported by BIOMA as a direct effect of changing climatic parameters. As there is no direct link of CAPRI with the climate change scenarios, the BIOMA platform and CAPRI naturally have the same climate assumptions in the scenarios. For this paper, the BIOMA used two A1B emissions climatic scenarios; a 'warm scenario' provided by the HadCM3 model (the realization is denoted as METO-HCHadRM3Q0-HadCM3Q0) and a 'mild scenario' provided by the ECHAM5 model (denoted DMI-HIRHAM5ECHAM5). ${ }^{2}$ The warm scenario estimates more than $3^{\circ} \mathrm{C}$ increase $^{3}$ while the mild scenario limits the average temperature to $1^{\circ} \mathrm{C}^{4}$ in 2020 compared to the average temperature in Europe in the year 2000. The precipitation regime also shows a substantial difference in these two scenarios. The warm scenario shows a much stronger increase in precipitation especially around south of Alps and southern Spain relative to year 2000 (up to $100 \%$

\footnotetext{
${ }^{1}$ The effects of elevated CO2 on crop growth and yield included in the BIOMA platform are consistent with current findings (e.g. Tubiello et al. 2008). Nonetheless, it is widely expected that CO2 response in farmers' fields will be lower than found experimentally, so that the functions implemented in the simulations of this paper are likely to represent an overestimate of actual field responses.

2 The scenario names are chosen for convince for a better presentation of the results and reflect the expected temperature rise in 2020. Under the 'warm scenario' the expected temperature increase in 2020 is higher than under the 'mild scenario' (see further).

${ }^{3}$ In 'warm' scenario in most of Central and Eastern Europe projections show warmer winters whereas there is little change in the Iberian Peninsula. In spring and summer, the gradient is not so evident since (mild) rises in temperature seem limited to the Atlantic coast for most of EU-27. Some parts of Italy even see lower temperatures than in the baseline. However, Eastern Europe and Finland are expected to see a much stronger rise in summer temperature.

${ }^{4}$ The 'mild' scenario projects only a small increase in minimum and maximum air temperature during the main crop growing season (April to September) with sporadic patterns throughout Central and Eastern Europe. Only the maximum temperature over the Iberian Peninsula shows a consistent spatial pattern of increase, whereas some decrease in maximum temperature is also seen in Ireland.
} 
a) No-adaptation

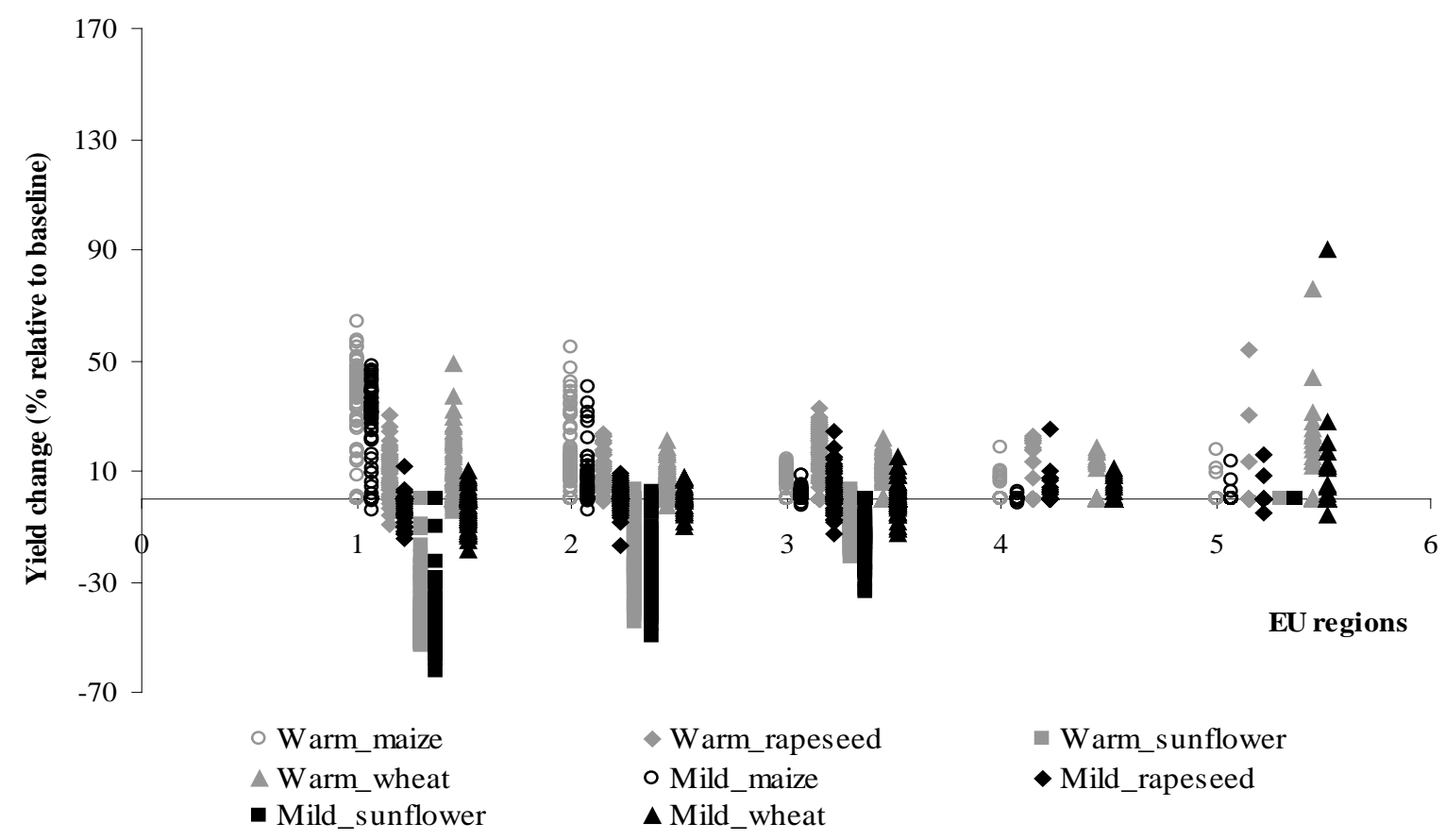

a) Best-adaptation

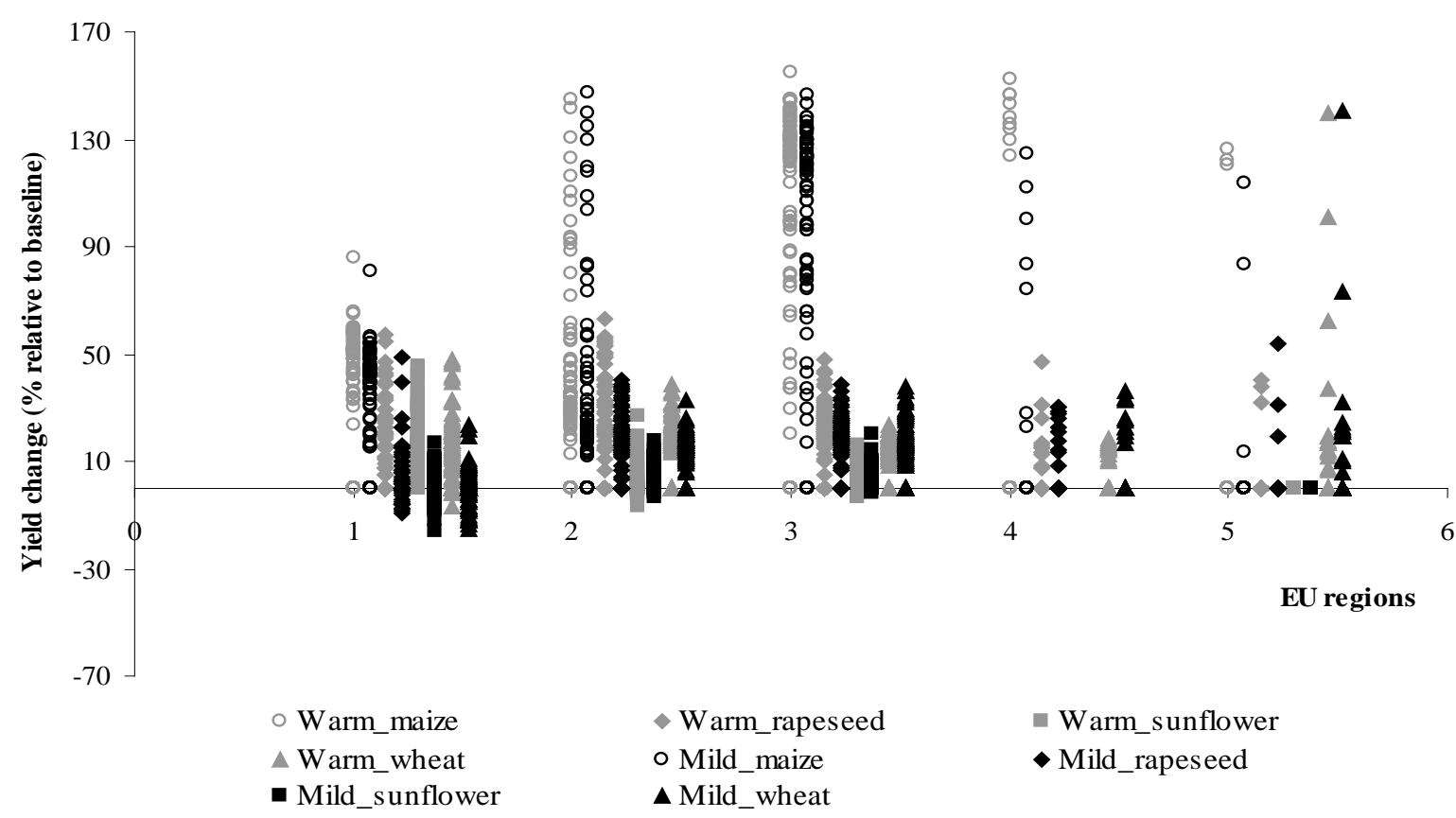

Notes: 1 = Southern Europe; 2 = Central Europe South; 3 = Central Europe North; 4 = British Isles; and 5 = Northern

Figure 1 Yield changes in climate change scenarios by NUTS-2 and EU zones (\% change relative to baseline)

increase) whereas the precipitation under the mild scenario do not show any dramatic change. The Iberian Peninsula and most of the Western Europe gets drier growing season but Scandinavian countries and France do get an increase in precipitation.

Once the BIOMA yield data has been completed each yield change data set is imported into CAPRI for the corresponding scenario. The yield changes alter variable costs (e.g. fertilizers) in CAPRI linked to adjustment of production intensity. They then help to determine the context in which CAPRI assumes that producers make their supply decisions so as to maximise profit. The BIOMA model provided the yield change data for four crops; wheat, rapeseed, sunflower and maize. However, the CAPRI has more disaggregated crops in the model than these four crops. Hence yield changes for CAPRI crops that are not provided by the BIOMA model are assumed to be same as the yield change for a similar BIOMA crop; for instant for barley which is not available in BIOMA, yield change for wheat is assumed. 
For some crops such as vegetables and fruits, an aggregated change in yield for the BIOMA crops is assumed. This applies to grass yield as well as grass data was not available from the BIOMA model and hence change in yield is assumed to be the same as aggregated change in yield for the BIOMA crops. It should also be mentioned here that the BIOMA provided the yield change data for 2020 at the NUTS-2 regions. The NUTS2 regional coverage of the CAPRI and the BIOMA dataset are compared and any missing regional data were estimated based on similar neighbouring regions.

Under each of the climate scenario, the BIOMA projected crop yield data under two adaptation scenarios; 'no-adaptation' and 'best-adaptation' scenarios. The adaptation is captured through adjustments in the crop growth cycle length, crop sowing date and water availability (irrigation) (Table 1). The two scenarios reflect two possible extreme situations that climate change may induce. The former scenario does not consider any potential adjustments by farmers (in terms of cycle length, crop sowing date and water availability) under climate change. This is unrealistic since one would expect farmers to react in an attempt to realise the maximum yield potential in the new climatic conditions. Thus, the no adaptation scenario provides one theoretical bound of possible climate change effects on yield. The best-adaptation scenario assumes the farmer adapts by optimally adjusting the combination of the crop growth cycle length, crop sowing date and water availability (depending on the crop) in such a way as to generate the highest possible yield for a given crop. ${ }^{5}$ This maximum degree of adaptation is also highly unlikely and represents the theoretical opposite bound of climate change effects on yield. In reality, the expected impact of climate change will be in between the two scenarios considered.

The yield changes for the two adaptation scenarios under each of the climate change scenarios are provided in Table 2 and Figure 1 for selected crops, for no-adaptation and best-adaptation scenarios and for five EU zones ${ }^{6}$. Table 2 shows weighted average yield changes $^{7}$ and Figure 1 shows their dispersion across NUTS-2 regions. Overall, climate change results in positive yield changes for wheat, maize and rapeseed for no-adaptation scenario across regions with exception of wheat for Southern Europe in mild scenario. In contrast, sunflower yield responds negatively to climate change when no-adaptation is considered. These effects are driven among others by favourable changes in temperature and rainfall during the growing season for

\footnotetext{
${ }^{5}$ We consider cost of adaptation directly linked to yield changes (e.g. costs of fertilizers). We do not consider other costs associated with adaptation given the fact that costs of adaption considered in BIOMA (changing sowing date or growth cycle) is likely minimal and rather difficult to estimate.

${ }^{6}$ For the sake of easier interpretation, we aggregated regions into five EU zones: Southern Europe (Portugal, Spain, Italy, Greece, Cyprus, Malta and Bulgaria); Central Europe South (France, Austria, Czech Republic, Slovakia, Hungary, Romania, and Slovenia); Central Europe North (Belgium, The Netherlands, Germany, Luxemburg and Poland); British Isles (Ireland and UK); and Northern Europe (Denmark Sweden, Finland, Estonia, Latvia, and Lithuania).

${ }^{7}$ Land area in baseline was used as weights.
}

latter three crops which stimulates their yields, whereas the change in temperature and rainfall during its growing season of sunflower is affected negatively (e.g. less rainfalls) by climate change. The growing season of sunflower differs in particular with respect to wheat and rapeseed implying that the temperature and rainfall are affected by climate change differently within a year. On average for EU yield changes vary between $-37 \%$ and $20 \%$ depending on scenario and crop. Weighted average yield changes in the warm scenario tend to be higher than in the mild scenario due to climate change induced more favourable changes in temperature and rainfall patterns in the former scenario than in latter one. An exception to this rule is sunflower where there is no significant difference between warm and mild scenarios due to the fact that climatic conditions relevant for sunflower during its growth season do not differ markedly between the two scenarios (Table 2). ${ }^{8}$ The absolute yield changes with no-adaptation tend to increase if moving from Southern to Northern Europe for wheat and rapeseed. For maize and sunflower the reverse holds. Similar pattern is observed also in Figure 1 where yield changes for NUTS-2 regions are displayed. According to this figure, yield changes at NUTS-2 level for the four crops varies between $-70 \%$ and $90 \%$ with sunflower being predominantly in negative territory and other crops being predominantly in positive territory across regions. When best-adaptation is considered, the yields improve significantly indicating that the crop growth cycle length, crop sowing date and water availability may be important factors driving adjustments of the agricultural sector to climate change. Most crops and regions experience and increase in yields and the size of yield change is in many regions more than twice larger than for no-adaptation scenario. At EU level, yield changes vary between 4\% and 62\% depending on scenario and crop (Table 2). Maize is affected stronger than other crops because BIOMA assumes no constraint of water availability through irrigation which importantly stimulates improvement of yields in particular in Central and Northern Europe. ${ }^{9}$ For other crops adaptation through irrigation is not considered (Table 1). ${ }^{10}$ Yield change at NUTS-2 level with best-adaptation for the four crops varies between $-20 \%$ and $170 \%$. Most volatile among four crops is maize for all regions and wheat for Northern Europe (Figure 1). Overall, the results reported in Table 2 and Figure 1 reveal that (i) there is a positive overall impact of climate change on yields, (ii) the gain from technical adaptation might be substantial and (iii) there is strong regional variation of climate impacts.

\footnotetext{
${ }^{8}$ Note that climate change affects overall yearly temperature and rainfall levels as well as their fluctuations within a year, hence crops respond differently as their growing season differs between different crop types.

${ }^{9}$ In Sothern Europe irrigation is used extensively for maize in the baseline scenario with no-climate change, hence its additional positive effect on yield in the presence of climate change is smaller than in other regions. Note that the assumption of no constraint of water availability for irrigation in BIOMA may bias maize yield effects upward.

${ }^{10}$ In general this is consistent with current farm practices where irrigation is applied to a lesser extent for wheat, rapeseed and sunflower.
} 
In CAPRI modelling, we further divided each of the climate scenarios into two more scenarios (warm, mild, warm-global and mild-global) for this paper. A lack of data on changes in crop yields for the non-EU countries forced us to first look at the effects of climate change on the EU agriculture without any effect (especially the global market price effect) and then to include the market price effects also assuming that there is no change in the non-EU agriculture sector under climate change. The first two scenarios, warm and mild' scenarios, assume fixed prices of agricultural commodities. They simulate supply response of EU agriculture to climate change without taking in consideration market price effects. The other two scenarios ('warm-global' and 'mild-global') consider adjustment of EU and world prices of agricultural commodities to supply shock induced by climate change. We consider both EU and non-EU price adjustments. As the climate scenarios are introduced only for the European countries and crop yields are assumed to be unchanged in the non-EU countries, the price effects might be biased downward or upward depending on the supply response to climate change in non-EU regions and its impact on global commodity markets.

Hence, this paper uses 9 scenarios in total. First we include two adaptation scenarios: no-adaptation and best-adaptation. For each adaptation scenario we run two climate scenarios with fixed prices (warm and mild) and two climate scenarios with price effects (warm-global and mild-global). Additionally, we consider baseline scenario which defines the reference situation and thus serves as a comparison point for the 8 counterfactual scenarios. For the current paper, the baseline captures developments in exogenous variables, such as policy changes, population growth, GDP growth and agricultural market development, for the year 2020. It relies on a combination of three information sources (for a detailed description, see Britz and Witzke 2008): (1) most importantly, the Aglink-COSIMO baseline prepared for this project at the JRC-IPTS (Joint Research Centre - Institute for Prospective Technological Studies), (2) analysis of historical trends and (3) expert information (Blanco Fonseca et al. 2010).

\section{RESULTS AND DISCUSSION}

\section{Prices and production}

The simulation results indicate that climate change will reduce prices of agricultural commodities in the EU. ${ }^{11}$ The price changes occur in the warm-global and mildglobal scenarios because we allow both EU and Non-EU price adjustments in these scenarios. The price decrease under the no-adaptation scenario was lower than in the best-adaptation scenario except for sunflower, the price of which actually increases when adaption is not considered on farm. For rest of the crops the decrease in price corresponds to increase in yields. EU agricultural prices decrease with a maximum rate of $-27 \%$ relative to the baseline. The highest price impact is observed for maize and rapeseed due to strong yield effect of climate change (

Table 3). The difference in the mild and warm scenarios varies by crop and in general they follow the yield changes. Prices tend to decrease more in the warm-global scenario than in mild-global scenario consistent with yield changes.

In general, climate change tends to have positive impact on agricultural production due to higher yields although there are strong differences in adjustment pattern between sectors. Overall production changes mirror yield changes. Under no-adaptation scenario, cereal production increases within a range of $3 \%$ to $17 \%$ in all four scenarios in EU-27 (Table 4). However, there is a large regional variation in cereal production in the EU (Figure 2a). A large part of Spain and some parts of Central and Eastern Europe have a negative impact on cereal production under mild and mild-global scenarios due to reduction in yields driven by drier growing seasons in the former region and due to increased temperature in main crop growing season in the latter regions. In particular the strong difference in cereal production in mild scenario relative to warm scenario change observed in Spain in Figure $2 \mathrm{a}$ is due to differences in projected precipitation levels in the two scenarios. In warm scenario precipitation increases whereas in mild scenario lower precipitation is observed during growing seasons as a result of climate change. For oilseeds, there is an increase in rape seed production (up to $23 \%$ ) but sunflower seed production decreases around $38 \%$ in these two scenarios in no-adaptation situation in the EU-27. The regional variation for oilseed production is large under all four scenarios (Figure 3a) as southern and Eastern Europe have a large decrease in production. Under best-adaptation scenario, production for both cereal and oilseeds increases in all four scenarios, between $25 \%$ and $35 \%$. However, there is strong difference between crops. Due to high yield effects of climate change, maize production increase much more than other crops. In contrast sunflower increases the least due to small yield adjustment. The mild scenario results in smaller production effects as compared to the warm scenario. At the regional level, the production improves in most of the regions under the best-adaptation scenario compared to the no-adaptation scenario (Table 4; Figure 2b; Figure 3b).

Adjustment of animal production to climate changes is relatively lower but positive in all four scenarios. The overall increase in animal production is induced by lower crop prices which reduce animal feed costs (in the global scenarios) and higher yield level of feed crops (e.g. grassland) (in all scenarios) (Table 4). Note that the smaller animal production adjustment could be due to the fact that we assumed zero impact of climate change on animal yields. This is based on the assumption that the direct effect of climate change on individual animals would be very small for the next fifty years (Parsons et al. 2001).

\footnotetext{
${ }^{11}$ Note that we implement climate change scenario only in European courtiers which implies that the actual price effects may be different.
} 
Table 2 Yield changes in climate change scenarios by EU zones (\% change relative to baseline)

\begin{tabular}{|c|c|c|c|c|c|c|c|c|}
\hline & \multicolumn{2}{|c|}{ Wheat } & \multicolumn{2}{|c|}{ Maize } & \multicolumn{2}{|c|}{ Rapeseed } & \multicolumn{2}{|c|}{ Sunflower } \\
\hline & Warm & Mild & Warm & Mild & Warm & Mild & Warm & Mild \\
\hline \multicolumn{9}{|c|}{ No-adaptation } \\
\hline Southern Europe & 9.7 & -4.0 & 30.9 & 17.8 & 4.5 & 0.0 & -43.9 & -44.6 \\
\hline Central Europe South & 8.4 & 2.6 & 21.4 & 10.0 & 9.0 & 0.7 & -31.1 & -32.1 \\
\hline Central Europe North & 13.9 & 0.0 & 9.6 & 2.4 & 23.8 & 6.7 & -16.9 & -27.2 \\
\hline British Isles & 15.3 & 4.4 & 9.3 & -0.5 & 18.1 & 7.0 & & \\
\hline Northern Europe & 22.4 & 6.9 & 10.5 & 6.4 & 20.9 & -0.6 & & \\
\hline EU & 11.6 & 1.0 & 19.8 & 9.3 & 15.7 & 3.4 & -36.0 & -37.0 \\
\hline \multicolumn{9}{|c|}{ Best-adaptation } \\
\hline Southern Europe & 16.0 & -1.0 & 42.2 & 30.3 & 35.9 & 25.5 & 16.0 & 1.4 \\
\hline Central Europe South & 22.5 & 17.3 & 38.7 & 31.8 & 34.1 & 23.3 & 5.9 & 5.6 \\
\hline Central Europe North & 15.9 & 18.6 & 117.7 & 111.9 & 28.2 & 23.7 & 8.5 & 3.3 \\
\hline British Isles & 14.6 & 23.5 & 141.4 & 80.1 & 14.0 & 24.8 & & \\
\hline Northern Europe & 19.4 & 23.3 & 121.7 & 85.9 & 33.6 & 24.9 & & \\
\hline EU & 18.6 & 14.5 & 61.9 & 53.2 & 29.8 & 23.7 & 9.9 & 3.9 \\
\hline
\end{tabular}

Table 3 Producer price changes in EU-27 (\% change relative to baseline)

\begin{tabular}{lccccc}
\hline & Baseline & \multicolumn{3}{c}{ Percentage change relative to the baseline scenario } \\
\cline { 3 - 6 } & & \multicolumn{2}{c}{ No-Adaptation } & \multicolumn{2}{c}{ Best-adaptation } \\
\cline { 2 - 5 } & & Warm-global & Mild-global & Warm-global & Mild-global \\
\hline Cereals & 144.1 & -10.2 & -2.4 & -19.2 & -17.8 \\
Soft wheat & 139.6 & -9.0 & -2.2 & -15.27 & -14.9 \\
Barley & 147.3 & -10.4 & -2.1 & -18.8 & -16.7 \\
Grain maize & 155.6 & -12.7 & -4.0 & -24.5 & -21.8 \\
Oilseeds & 318.4 & -6.7 & 2.9 & -22.2 & -18.9 \\
Rape seed & 318.6 & -16.4 & -4.1 & -26.1 & -23.1 \\
Sunflower seed & 313.5 & 37.8 & 34.6 & -11.6 & -6.6 \\
Meat & 1939.3 & -2.9 & -0.4 & -6.1 & -5.6 \\
Beef & 3223.2 & -3.2 & -0.3 & -7.4 & -6.8 \\
Milk & 265.1 & -3.8 & -0.2 & -9.4 & -8.7 \\
\hline
\end{tabular}

Source: calculated

Table 4 Production change in EU-27

\begin{tabular}{|c|c|c|c|c|c|c|c|c|c|}
\hline & \multirow{3}{*}{$\begin{array}{c}\text { Baseline } \\
\text { (million } \\
\text { tones) }\end{array}$} & \multicolumn{8}{|c|}{ Percentage change relative to the baseline } \\
\hline & & \multicolumn{4}{|c|}{ No-adaptation } & \multicolumn{4}{|c|}{ Best-adaptation } \\
\hline & & Warm & Mild & $\begin{array}{l}\text { Warm- } \\
\text { global }\end{array}$ & $\begin{array}{l}\text { Mild- } \\
\text { global }\end{array}$ & Warm & Mild & $\begin{array}{l}\text { Warm- } \\
\text { global }\end{array}$ & $\begin{array}{l}\text { Mild- } \\
\text { global }\end{array}$ \\
\hline Cereals & 323.4 & 16.6 & 4.3 & 9.6 & 2.8 & 35.2 & 31.3 & 18.4 & 16.5 \\
\hline Soft wheat & 142.2 & 13.3 & 2.9 & 7.5 & 1.8 & 21.6 & 23.0 & 10.8 & 12.2 \\
\hline Barley & 61.9 & 13.0 & 1.1 & 6.7 & 0.2 & 20.1 & 15.2 & 7.9 & 4.9 \\
\hline Grain maize & 67.8 & 28.4 & 13.6 & 16.3 & 9.8 & 65.9 & 54.2 & 33.7 & 28.2 \\
\hline Oilseeds & 33.1 & 7.7 & -4.2 & -1.2 & -4.8 & 32.2 & 25.8 & 10.5 & 7.9 \\
\hline Rape seed & 24.1 & 22.7 & 6.6 & 6.3 & 2.2 & 39.8 & 33.8 & 11.3 & 9.5 \\
\hline Sunflower seed & 7.3 & -38.5 & -37.9 & -25.1 & -26.5 & 10.2 & 3.3 & 6.1 & 2.4 \\
\hline Beef & 9.6 & 1.5 & -1.0 & 5.7 & -0.4 & 6.4 & 5.7 & 14.7 & 12.8 \\
\hline Milk & 149.8 & 0.7 & 0.5 & 0.6 & 0.0 & 1.6 & 1.5 & 1.5 & 1.3 \\
\hline
\end{tabular}

Price adjustments of agricultural commodities tend to reduce the impact of climate change on production. Comparing scenarios with market price effects (warm-global, mild-global) and scenarios where only supply adjustments are considered (warm, mild), production change is substantially lower in the former 
two scenarios as compared to the latter two scenarios (Table 4). This is valid in particular for crop sectors. For animal sector, production adjustment is also linked to crop price effects which reduce feed costs in global scenarios leading to higher production of beef relative to scenarios where only supply response is considered (warm, mild). Milk relies heavily on grassland for feed and as a result the price effect is smaller due to the fact that grassland is non-tradable and its shadow price is affected by return from diary production and by the substitution effect with arable crops (Table 4).

The findings of other studies on the impact of climate change on European agricultural productivity for 2020 show relatively high variability. However, one must bear in mind that the comparability of results between different studies is often difficult due to differences in methodology, scenario assumptions and comparison base. Overall our results tend represent a higher bound of the possible impact of climate change on European Agriculture. In broad lines our results are consistent with results of Hisas (2011) and IPCC (2007) who report climate-related increases in crop yields in 2020 occurring mainly in northern Europe, while the reductions are expected in the Mediterranean basin and in south-east Europe. The results of Monti (2010) show that the increases in crop productivity for Europe in 2020 will be from $25 \%$ to $41 \%$, mostly due to technological development and to a lesser extent to $\mathrm{CO} 2$ increase (about 4\% in 2020) and climate change (about 1\%). Ewert et al. (2005) estimate average yield changes across EU to be small in 2020 as yield gains and losses largely averaged out and ranges between 1 and $-3 \%$. According to Ewert et al. (2005) climate change resulted in higher yields compared to the baseline in the North of Europe, lower yields in the South of Europe (mainly in Spain and Portugal and to some extend in France and Italy) and small effects were estimated for Central and Western Europe. Parry et al. (2004) estimate potential impacts of a set of climate change scenarios developed from the HadCM3 global climate model under the Intergovernmental Panel on Climate Change Special Report on Emissions Scenarios (SRES). Their results for Europe indicate that cereal yields will change due to climate change between $-5 \%$ and $5 \%$ in 2020 relative to 1990. Parry et al. (2004) further note that these changes are within historical variations.

\section{Land use}

The impact of climate change on EU aggregate land use is relatively small. Total utilized agricultural area (UAA) in EU slightly decreases (maximum -0.5\%) relative to the baseline in the warm and mild scenarios in both adaptation scenarios (Table 5). This effect is driven by grassland which more than offsets the arable land increase in warm and mild scenarios. Area of most arable crops reacts positively to climate change because of improved yields and land productivity. The main exception is sunflower which loses relative to other crops in particular in no-adaptation scenario. Aggregate arable land follows this pattern and in general its level expands. There is also a slight substitution of pastures for arable land as farmers shift production to higher yielding crops such as maize and rapeseeds in particular under the bestadaptation scenario. At the same time, higher grass yields allow livestock sector to obtain feed needs from less pasture land leading to decline in pasture land in the EU. Overall at the EU level, the arable land effect is smaller than the pasture land effect causing a reduction in the UAA. In several regions and countries where arable sector is dominant UAA tends to expand (e.g. Estonia, Hungary, the Czech Republic), whereas in others with important livestock sector the UAA reduction is much stronger than the EU average (e.g. Netherlands). Compared to changes in the UAA, more significant in terms of relative change are land relocation effects between different crops in warm and mild scenarios; they vary between $-8 \%$ and $10 \%$ (Table 5). Although these patterns are consistent across both adaptation scenarios, under the best-adaptation situation they are more pronounced: their magnitude and variation across crops and regions is larger.

In global scenarios the UAA reduces more significantly (up to $-2.3 \%$ ) due to the price effect which reduces agricultural profitability and offsets production gain and hence leads to drop in demand for land. With no-adaptation, most land categories decrease in warm

Table 5 Land use change in EU-27 (\% change relative to baseline)

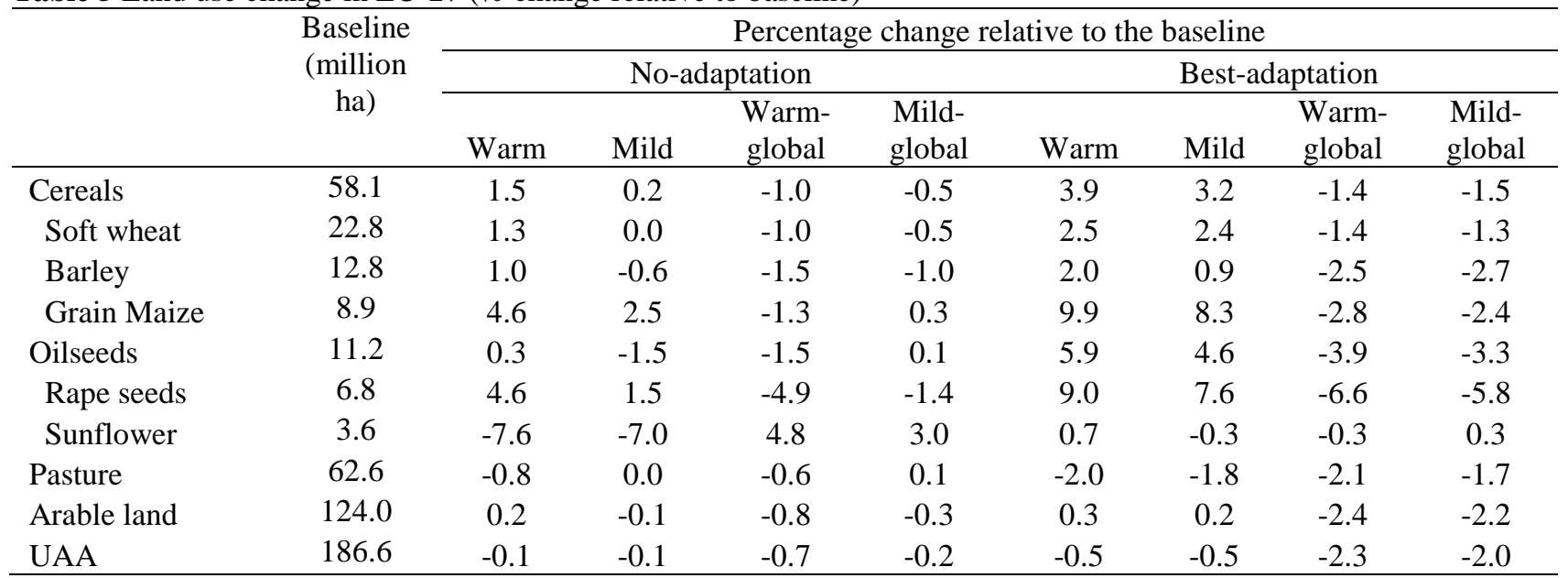

Table 6 Welfare and agriculture income in EU-27 (\% change relative to baseline) 


\begin{tabular}{lcccccccc}
\hline & Warm & Mild & $\begin{array}{c}\text { Warm- } \\
\text { global }\end{array}$ & $\begin{array}{c}\text { Mild- } \\
\text { global }\end{array}$ & Warm & Mild & $\begin{array}{c}\text { Warm- } \\
\text { global }\end{array}$ & $\begin{array}{c}\text { Mild- } \\
\text { global }\end{array}$ \\
\hline Total welfare & & & 0.08 & 0.0 & & & 0.02 & 0.2 \\
Agricultural income & 3.3 & 0.8 & -0.2 & -0.2 & 8.0 & 6.8 & -0.1 & -0.3 \\
\hline Soure:
\end{tabular}

global scenario (between -0.5\%and -5). Only sunflower area expands by $5 \%$. In mild-global scenario, the land use adjustment is much lower for most land categories varying between $-0.5 \%$ and $0.5 \%$. With best-adaptation, downward adjustment in land area is more pronounced driven by stronger price and income reduction; area of most land categories declines between $-1 \%$ and $-3 \%$ (Table 5).

At regional level climate change tends to cause stronger impact on land use in the Central and Northern EU. There are regions which experience an increase in land use but some regions in the Central and Northern EU decrease the UAA particularly in global scenarios with best-adaptation. Whereas in global scenarios most of the regions reduce the UAA and none expand. This land use adjustments are more visible in scenarios with best-adaptation. In the case when no-adaptation is assumed, the magnitude of adjustments and the number of affected regions are smaller relative to best-adaptation case. In Southern EU (with exception of Northern Spain and Northern Italy) the effects of climate change are minor. The UAA is almost unaffected (it changes between $-1 \%$ and $0 \%$ ). Only in global scenario with bestadaptation there are observed some substantive changes in Northern Spain and Northern Italy (Figure 4).

\section{Income and welfare effects}

Climate change will lead to a small positive impact on total welfare (Table 6). The total welfare improves due to consumer gain from lower food prices but the change is very small (close to zero). The agricultural income reacts stronger but the effect is still relatively low: between -0.1 and $8 \%{ }^{12}$ In the warm and global scenarios, the agricultural income improvement (between $0.8 \%$ and 3\% with no-adaptation and between $7 \%$ and $8 \%$ with bestadaptation) is caused by overall increase in yields. When considering adjustment of prices (warm-global and mildglobal scenarios), the income change is negative but rather small. This is a standard result in agricultural economics. Since most agricultural products have inelastic demands, farmers typically see their incomes dwindling when there is improvement in productivity. Price reduction more than offsets the gain from production increase causing agricultural income to drop between $-0.1 \%$ and $-0.3 \%$ for global scenarios.

The variance in agricultural income change is much stronger at regional level. More than $80 \%$ NUTS-2 regions experience income increase when only supply adjustments is considered (warm and mild scenarios), whereas $50 \%$ or more regions experience reduction of income when adjustment of prices is considered (warm-

\footnotetext{
12 The calculation of the income of the agricultural sector follows the concept of the gross value added. This is the value of the total outputs increased with subsidies minus the value of intermediate inputs.
}

global and mild-global scenarios) (Figure 5). Under noadaptation scenario, the income change varies between $29 \% \%$ and $39 \%$. In best-adaptation scenario, the income change varies between $-55 \%$ and $45 \%$.

Although from an individual farmer's perspective adaptation may not seem the ideal option, adaptation is always a rational choice because farmers are price takers and cannot individually affect market prices. As adaptation is a rational choice for all farms, aggregate production increases but market prices respond in the opposite direction. In relative terms prices tend to fall more than production expands because consumers' reaction to increased food availability is a significant reduction in the price they are willing to pay due to inelastic demand.

\section{CONCLUSIONS}

The current paper investigates the medium term impact of climate changes on the EU agriculture. We employ CAPRI modelling framework to identify the EU aggregate effects as well as regional impacts. We take into account supply and market price adjustments of the EU agricultural sector as well as technical adaptation of crops to climate change. Overall results indicate an increase in yields and production level in the EU agricultural sector due to the climate change. However, there will be both winners and losers, with some regions benefitting from agricultural production adjustment as a result of climate change while other regions suffering losses in production and welfare. In general, there are relatively small effects at the EU aggregate. For example, the value of land use and welfare change by approximately between $-2 \%$ and $0.2 \%$. However, there is a stronger impact at regional level with some stronger effects prevailing particularly in the Central and Northern EU (e.g. in terms of land use) and smaller impacts are observed in Southern Europe. Regional impacts of climate change increase by a factor higher up to 10 relative to the aggregate EU impacts. The price adjustments reduce the response of agricultural sector to climate change in particular with respect to production and income changes. For example, without price adjustment the agricultural income improves between $1 \%$ and $8 \%$ at EU level, whereas if price effect is accounted for agricultural income slightly declines (between $-0.1 \%$ and $-0.3 \%$ ) because downward price adjustment offsets 
a) No-adaptation
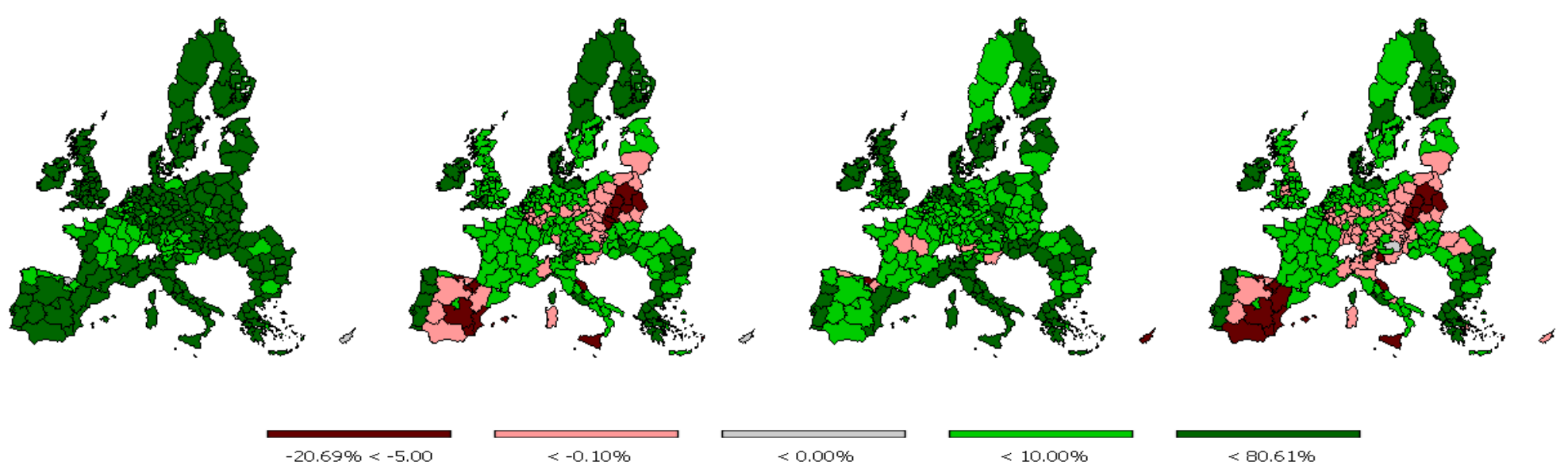

b) Best-adaptation
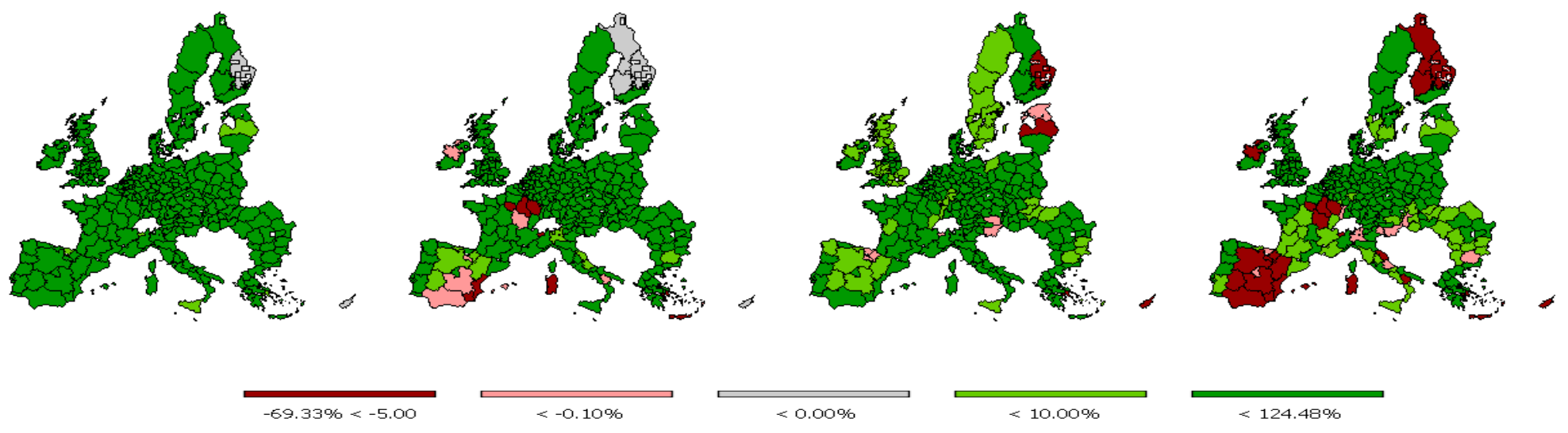

$<124.48 \%$

Figure 2 Change in cereal production in EU-27 (\% change relative to baseline) 
a) No- adaptation
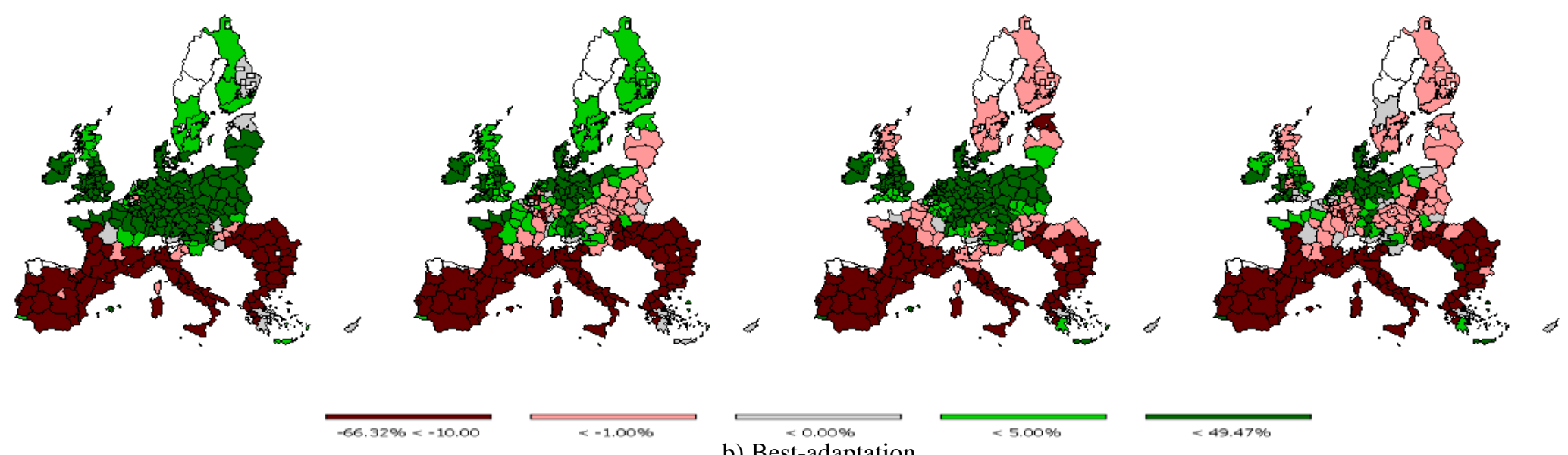

b) Best-adaptation
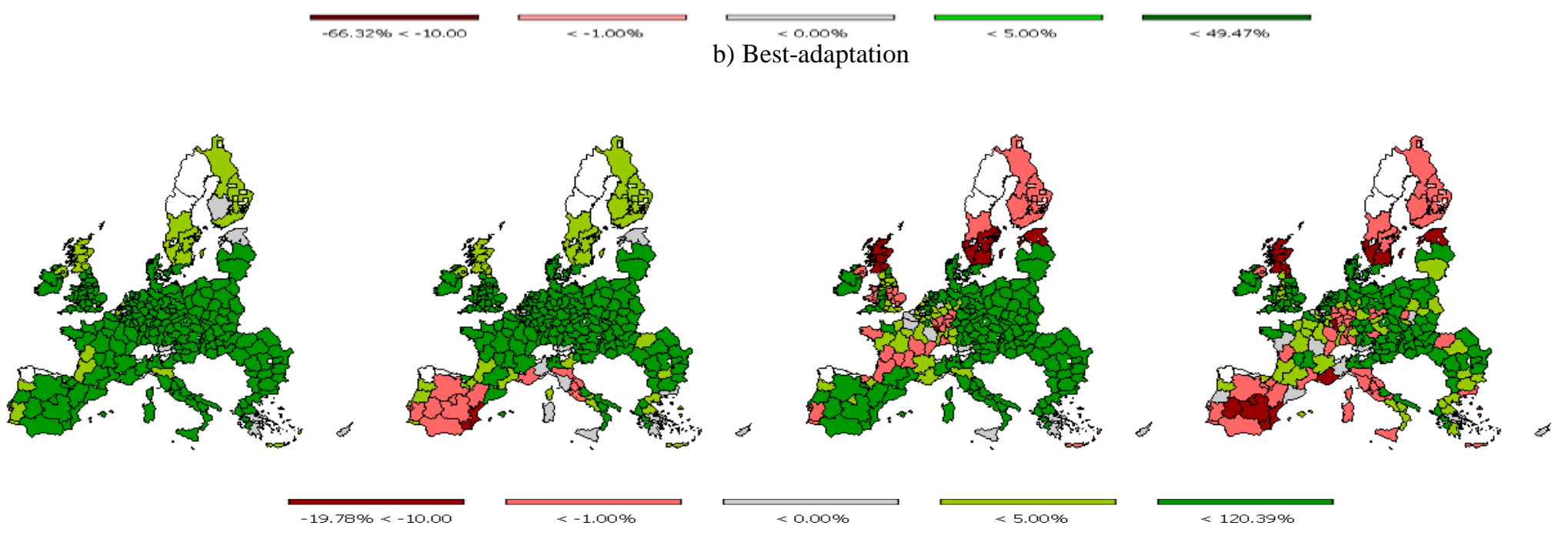

Figure 3 Change in oilseeds production in EU-27 (\% change relative to baseline) 

Warm
Mild
Warm-global
Mild-global

a) No- adaptation

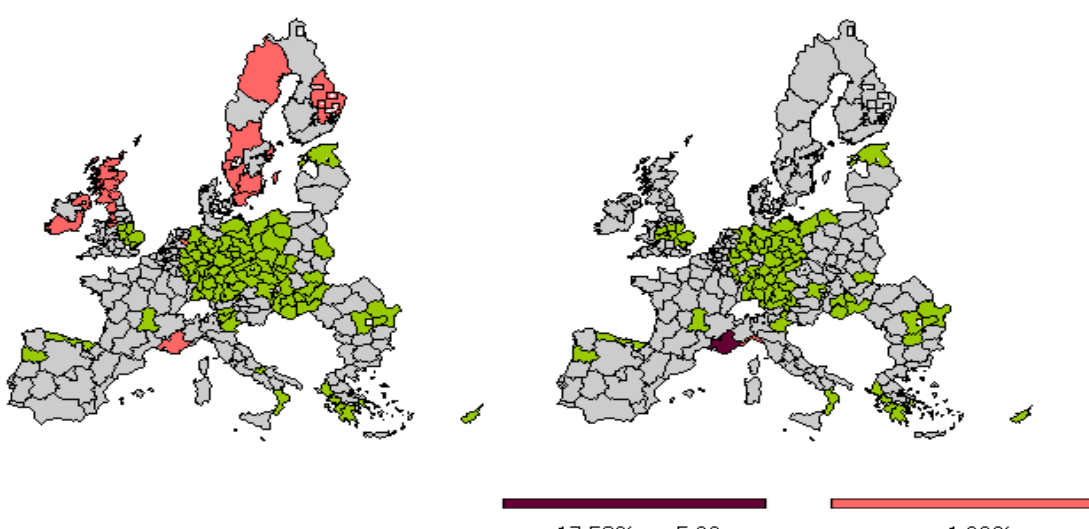

$-17.52 \%<-5.00$
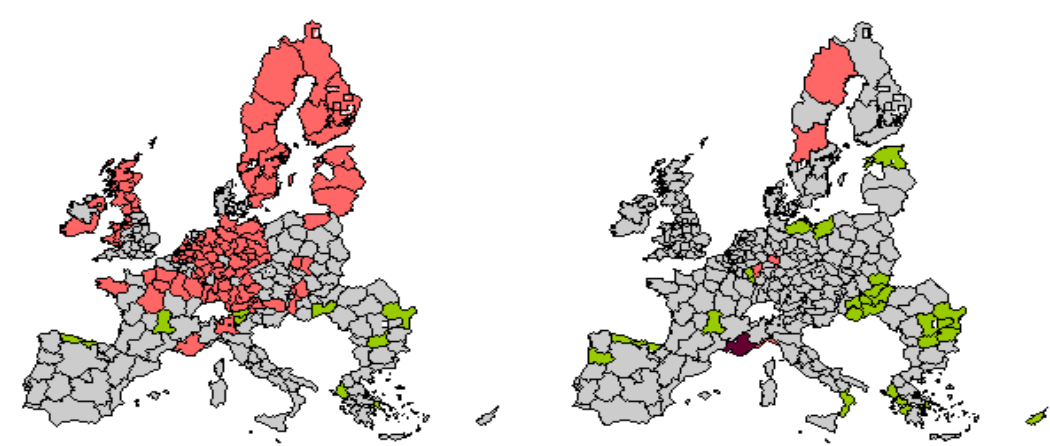

b) Best-adaptation
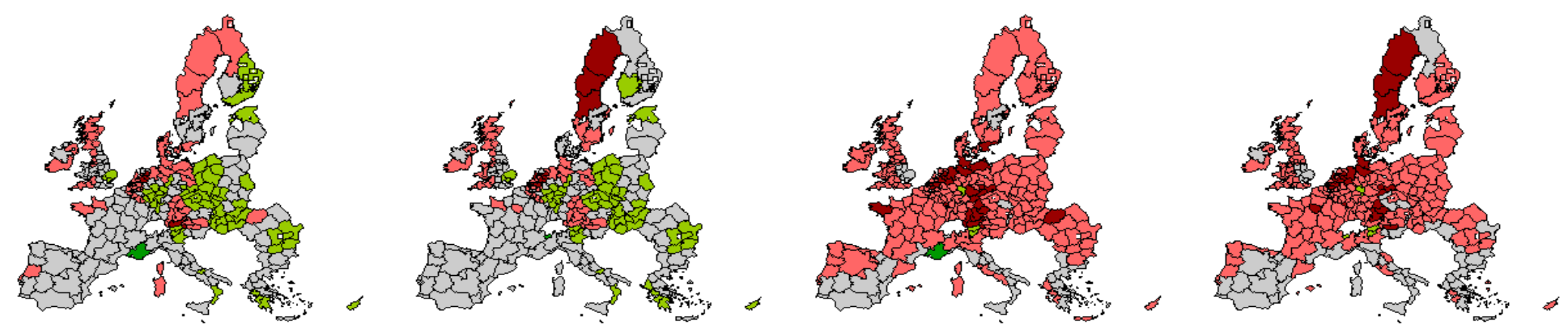

$-17.89 \%<-5.00$
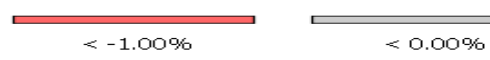

$<1.00 \%$

$<1.82 \%$

Figure 4 UAA land use change at NUTS-2 in EU-27 (\% change relative to baseline) 
Warm

Mild
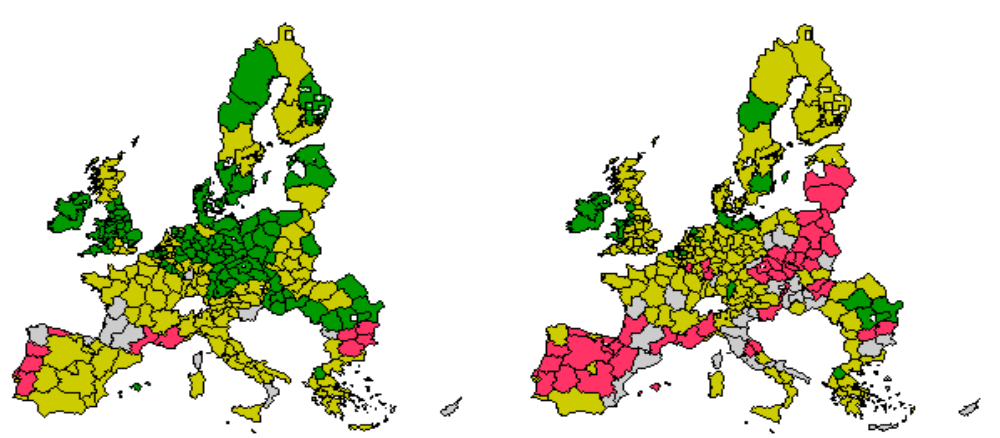

a) No-adaptation

Warm-global

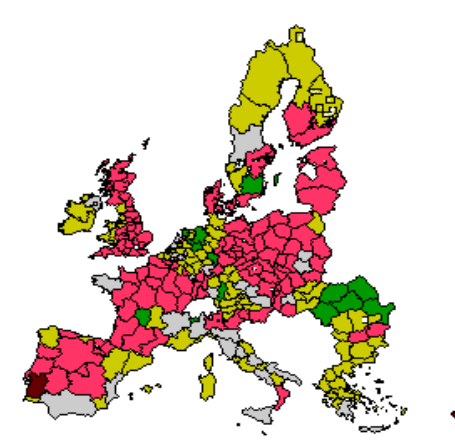

b) Best-adaptation
$<5.00 \%$

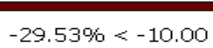

$<-1.00 \%$

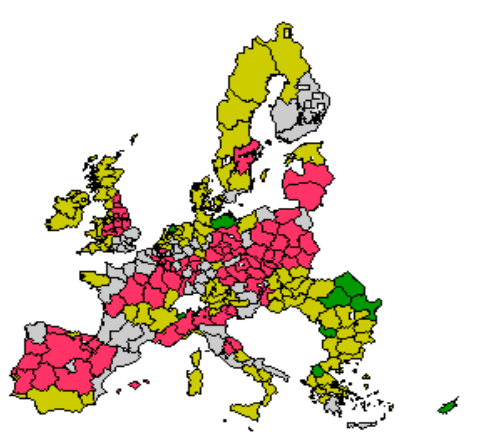

$<38.98 \%$
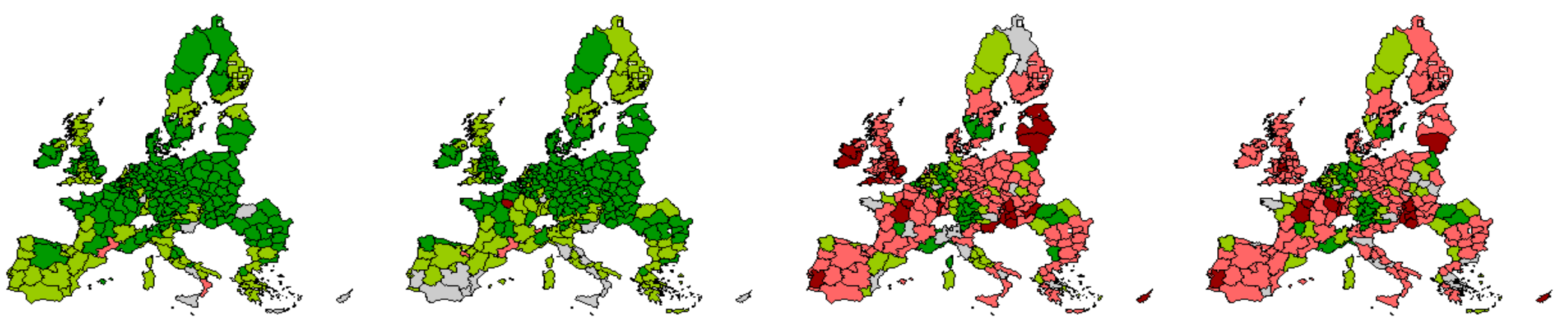

$-55.84 \%<-10.00$

$<0.00 \%$

$<5.00 \%$

$<45.37 \%$

Figure 5 Income change at NUTS-2 in EU-27 (\% change relative to baseline) 
the gain from production increase. Further, the simulation results indicate that the technical adaption of crops to climate change may result in a significant adjustment in yield, production, land use and incomes. For example, best-adaptation may change production and land use by a factor between 1.4 and 6 relative to noadaptation situation.

From a policy perspective our results indicate that targeting intervention (if any) might be more efficient if differentiated at regional level rather than implementing a uniform approach applied across the whole EU to address the climate effects. Indeed, regions are affected differently depending on the location and sector which requires a site specific adjustment to climate change. An effective policy design may thus require a micro regionalized approach with strong focus on local needs. Adaptation plays a key role in this respect as it may have substantial effects on the agricultural sector potentially leading to a $50 \%$ or more additional adjustments in production, land use and welfare. As a result, a key focus of the policy (if any) might be targeted towards supporting and addressing adaptation of the agricultural sector to climate changes.

The results in this paper must be analyzed in the context of limitations imposed on the paper. In particular we do not take into account full adaptation of the EU agricultural sector to climate changes. We consider only technical adaptation of crops in terms of growth cycle length, sowing date and water availability. We do not take into account economic adaptation such as changes in technology, management practices and farm structure. We investigate the medium term effect of climate change on the EU agriculture. A long term adjustment may mitigate some of the effects and the sectoral and/or regional impacts maybe stronger than our results indicate. The climate change scenarios are introduced only for the European countries and crop yields are assumed to be unchanged in the non-EU countries. Therefore the price effects in our results might be biased downward or upward depending on the supply response to climate change in non-EU regions and its impact on global commodity markets. The use of stylized template supply modules in CAPRI which are structurally identical and express differences between regions solely by parameters alone might fall short of capturing the full regional diversity of farming systems in the EU and their response to climate change. In particular, this is the case for the evaluation of climate change impact on cropping systems, technology adaptation, such as fertilization, manure handling, feeding practices and sectoral demand behaviour. The relatively simple representation of agricultural technology in the CAPRI model compared to approaches parameterised based on biophysical models understates the farm response to natural and local constraints. While some of the key drivers of the analysis of agriculture and climate change require a global perspective and modelling, the analysis of impacts will have to be context-specific and should not be estimated via analyses at a high level of abstraction. However, the current structure of the approach gives a good balance between increased detail of represented regions and robustness of the model results for medium term horizon economic analysis of climate changes.

Acknowledgments: The authors are grateful to Marcello Donatelli and Davide Fumagalli for providing climate change data for crop yields. The authors thank to anonymous referees, Juan Carlos Ciscar Martinez and Bert Saveyn as well as PESETA II workshop participants in Ispra and Seville for very useful comments on the article. The views expressed are purely those of the authors and may not in any circumstances be regarded as stating an official position of the European Commission.

\section{REFERENCES}

ADAMS, R.M. - HURD, B.H. - LENHART, S. LEARY, N. (1998a). Effects of global climate change on agriculture: an interpretative review. Climate Research. 11, 19-30. http://dx.doi.org/10.3354/cr011019

ADAMS, R.M. - MCCARL, B.A. - SEGERSON, K. ROSENZWEIG, C. - BRYANT, K.J. - DIXON, B.L. CONNER, R. - EVENSON, R.E. - OJIMA, D. (1998b). The economic effects of climate change on U.S. agriculture, Chap 2. In: Mendelsohn R, Neumann J (eds.). The economics of climate change. Cambridge University Press, Cambridge.

BATTS, G.R. - MORISON, J.I.L. - ELLIS, R. H. HADLEY, P. - WHEELER, T.R. (1997). Effects of $\mathrm{CO}_{2}$ and temperature on growth and yield of crops of winter wheat over four seasons. European Journal of Agronomy. 7, 43-52. http://dx.doi.org/10.1016/S11610301(97)00022-1

BAZZAZ, F. - SOMBROEK, W. (1996). Global climate change and agricultural production. Direct and indirect effects of changing hydrological, pedological and plant physiological processes. John Wiley, FAO (Rome, Italy). BLANCO-FONSECA, M. - BURRELL, A. - GAY, H. HENSELER, M. - KAVALLARI, A. - R. M'BAREK, R. - PÉREZ DOMÍNGUEZ, I. - TONINI A. (2010). Impacts of the EU Biofuel Target on Agricultural Markets and Land Use: A Comparative Modelling Assessment. JRC Scientific and Technical Report EUR 24449 EN.

BRERETON, A.J. - O'RIORDAN, E. (2001). A comparison of grass growth models. Holden, N. M. (Ed.). Agro-meteorological modelling - principles, Data and Applications. Agmet, Dublin pages 136-154.

BRITZ, W. - WITZKE, P. (2008) CAPRI model documentation 2008: Version 2. www.capri-model.org BROWN, R.A. - ROSENBERG N.J. (1999). Climate change impacts on the potential productivity of corn and winter wheat in their primary United State growing regions. Climatic Change. 41, 73-107.

CONFALONIERI, R. - ACUTIS, M. - BELLOCCHI, G. - DONATELLI, M. (2009). Multi-metric evaluation of the models WARM, CropSyst, and WOFOST for rice. Ecological Modelling. 11, 1395-1410.

CRAIGON, J. - FANGMEIER, A. - JONES, M. DONNELLY, A. - BINDI, M. - De TEMMERMAN, L. - PERSSON, K. - OJANPERA, K. (2002). Growth and marketable-yield responses of potato to increased $\mathrm{CO}_{2}$ 
and ozone. European Journal of Agronomy. 17, 273289. http://dx.doi.org/10.1016/S1161-0301(02)00066-7 CHANG, C. (2002). The potential impact of climate change on Taiwan's agriculture. Agricultural Economics. 27 , 51-64. $\quad$ http://dx.doi.org/10.1016/S0169-

5150(01)00060-3

CISCAR, J.C. (ed.) (2009). Climate change impacts in Europe Final report of the PESETA research project. JRC Scientific and Technical Research series EUR 24093 EN, European Commission, Joint Research Centre.

CUCULEANU, V. - MARCIA, A. - SIMOTA, C. (1999). Climate change impact on agricultural crops and adaptation options in Romania. Climate Research. 12, 153-160. http://dx.doi.org/10.3354/cr012153

DARWIN, R. - TSIGAS M. - LEWANDROWSKI, J. RANESES, A. (1995). World agriculture and climate change: economic adaptations. Agricultural Economic Report No. 703. Natural Resources and Environmental Division, Economic Research Service, U.S. Department of Agriculture, Washington, DC

EASTERLING, W.E. - CROSSON, P.R. ROSENBERG, N.J. - MCKENNEY, M.S. - KATZ, L. A. - LEMON, K.M. (1993). Agricultural impacts of and responses to climate change in the Missouri-IowaNebraska-Kansas (MINK) region. Climatic Change. 24, 23-61. http://dx.doi.org/10.1007/978-94-011-2096-8_3

EWERT, F. -ROUNSEVELL, M.D.A. -REGINSTER, I. - METZGER, M.J. -LEEMANS, R. (2005). Future scenarios of European agricultural land use I. Estimating changes in crop productivity. Agriculture, Ecosystems and Environment. 107, 101-116.

GHAFFARI, A. - COOK, H.F. - LEE, H.C. (2002). Climate change and winter wheat management: A Modelling scenario for south eastern England. Climatic Change. 55, 509-533.

GOCHT, A. - BRITZ, W. - CIAIAN, P. - GOMEZ y PALOMA, S. (2013). Farm Type Effects of an EU-wide Direct Payment Harmonisation. Journal of Agricultural Economics 64(1) 1-32. http://dx.doi.org/10.1111/1477$\underline{9552.12005}$

GORNALL, J. - BETTS, R. - BURKE, E. - CLARK, R. - CAMP, J. - WILLETT, K. - WILTSHIRE, A. (2010). Implications of climate change for agricultural productivity in the early twenty-first century. Philosophical Transactions of the Royal Society BBiological Sciences 365, 3-2989. http://dx.doi.org/10.1098/rstb.2010.0158

HAKALA, K. (1998). Growth and yield potential of spring wheat in a simulated changed climate with increased $\mathrm{CO}_{2}$ and higher temperature. European Journal of Agronomy. 9, 41-52. http://dx.doi.org/10.1016/S11610301(98)00025-2

HISAS, L. (2011). The Impacts of Climate Change on Food Production: A 2020 Perspective. Universal Ecological Fund. ISBN: 978-0-9831909-0-5, Available at: http://www.feu-us.org/images/The_Food_Gap.pdf HOLDEN, N. M. - SWEENEY, J. - BRERETON, A. J. - FEALY, R. (2004). Climate change and Irish agriculture. KEANE, T. - COLLINS, J. F. (Ed.), Climate
Weather and Irish Agriculture, Agricultural Meteorology, Met Eireann, Dublin, pages 359-382.

HOLDEN, N.M. - BRERETON, A.J. - FITZGERALD, J. B. (2008). Impact of climate change on Irish agricultural production systems. Climate change Refining the impacts for Ireland: STRIVE report. Environmental Protection Agency, Wexford, Ireland. pp. $82-131$.

IGLESIAS, A. - GARROTE, L. - QUIROGA, S. MONEO M. (2009). Impacts of climate change in agriculture in Europe. PESETA-Agriculture study. JRC Scientific and Technical Research series EUR 24107 EN, European Commission, Joint Research Centre.

IPCC, (2007). Climate Change 2007: Impacts, Adaptation and Vulnerability. Contribution of Working Group II to the Fourth Assessment Report of the Intergovernmental Panel on Climate Change. In. PARRY, M.L. - CANZIANI, O.F. - PALUTIKOF, J.P. - VAN DER LINDEN P.J. -HANSON, C.E. (Ed). (2007). Cambridge University Press, Cambridge, Available at: http://www.ipcc.ch/pdf/assessmentreport/ar4/wg2/ar4-wg2-chapter12.pdf

JONES, P. G. - THORNTON, P.K. (2003). The potential impacts of climate change on maize production in Africa and Latin America in 2055. Global Environmental Change. 13, 51-59. http://dx.doi.org/10.1016/S09593780(02)00090-0

LEIP A. - WEISS F. - WASSENAAR T. - PEREZ I. FELLMANN T. - LOUDJANI P. - TUBIELLO F. GRANDGIRARD D. - MONNI S. - BIALA K. (2010) Evaluation of the livestock sector's contribution to the EU greenhouse gas emissions (GGELS)-final report. European Commission, Joint Research Centre.

MONTI, A. (2010). Climate Change and Land Use Change. Deliverable of the FP7 project "Future Crops for Food, Fiber, and Fuel (4FCrops )"

MORISON, J.I.L. - LAWLOR, D.W. (1999). Interactions between increasing $\mathrm{CO}_{2}$ concentration and temperature on plant growth. Plant Cell Environment. 22, 659-682.

OLESEN, J.E. (2008). Climate change as a driver of European agriculture. Proceedings of the Conference on "Europe's rural areas in action: Facing the challenges of tomorrow" 16 -17 October 2008, Limassol, Cyprus, Available at: http://ec.europa.eu/research/agriculture/scar/pdf/scar_for esight_climate_change_en.pdf

OLESEN, J.E. - BINDI, M. (2002). Consequences of climate change for European agricultural productivity, land use and policy. European Journal of Agronomy. 16, (4) 239-262. http://dx.doi.org/10.1016/S11610301(02)00004-7

PARRY, M. L. - ROZENZWEIG, C. - IGLESIAS, A. LIVERMORE, M. - FISHER, G. (2004). Effects of climate change on global food production under SRES emissions and socio-economic scenarios. Global Environmental Change. 14, 53-67. http://dx.doi.org/10.1016/j.gloenvcha.2003.10.008 PARSONS, D. J. - COOPER, K. - ARMSTRONG, A. C. - MATHEWS, A. M. - TURNPENNY, J. R. CLARK, J. A. (2001). Integrated models of livestock 
systems for climate change studies. 1. Grazing systems. Global Change Biology. 7, 93-112.

PEIRIS, D.R. - CRAWFORD, J.W. - GRASHOFF, C. JEFFERIES, R.A. - PROTER, J.R. - MARSHALL, B. (1996). A simulation study of crop growth and development under climate change. Agricultural and Forest Meteorology. 79, 271-287. http://dx.doi.org/10.1016/0168-1923(95)02286-4

QUIROGA, S. - IGLESIAS, A. (2009). A comparison of the climate risks of cereal, citrus, grapevine and olive production in Spain. Agricultural Systems 101, 91-100. http://dx.doi.org/10.1016/j.agsy.2009.03.006

REIDSMA, P. - EWERT, F. - LANSINK, A.O. (2007). Analysis of farm performance in Europe under different climatic and management conditions to improve understanding of adaptive capacity. Climatic Change. 84, 403-422. http://dx.doi.org/10.1007/s10584-007-9242-7 ROSENZWEIG, C. - TUBIELLO, F.N. (1997). Impacts of global climate change on Mediterranean Agriculture, current methodologies and future directions: an introductory essay. Mitigation and Adaptation Strategies for Global Change. 1, 219-232. http://dx.doi.org/10.1007/BF00517804

ROTTER, R. - VAN DE GEIJN S. C. (1999). Climate change effects on plant growth, crop yield and livestock. Climatic Change. 43, 651-681.

SCHIMMELPFENNIG, D. - LEWANDROWSKI, J. REILLY, J. -, TSIGAS, M. - PARRY, I. (1996). Agricultural adaptation to climate change: issues of long run sustainability. Agricultural Economic Report No. 740. U.S. Department of Agriculture, Natural Resource and Environment Division Economic Research Service, Washington, DC.

STÖCKLE, C.O. - DONATELLI, M. - NELSON, R. (2003). CropSyst, a cropping system simulation model. European Journal of Agronomy. 18, 289-307. http://dx.doi.org/10.1016/S1161-0301(02)00109-0
SUPIT, I. - HOOIJER, A. - VAN DIEPEN, C. (1994). System Description of the Wofost 6.0 Crop Simulation Model Implemented in CGMS Joint Research Centre; European Commission.

SWEENEY, J. - BRERETON, T. - BYRNE, C. CHARLTON, R. - EMBLOW, C. - FEALY, R. HOLDEN, N. - JONES, M. - DONNELLY, A. MOORE, S. - PURSER, P. - BYRNE, K. - FARELL, E. - MAYES, E. - MINCHIN, D. - WILSON, J. WILSON, J. (2003). Climate Change: Scenario and Impacts for Ireland. The Impact of Climate change on Irish Agriculture - Final Report . Environmental Protection Agency, Ireland.

TUBIELLO, F. - SCHMIDHUBER, J. - HOWDEN, M. - NEOFOTIS, P.G. - PARK, S. - FERNANDES, E. THAPA, D. (2008). Climate change response strategies for agriculture: challenges and opportunities for the 21st century. Agriculture and Rural Development Discussion Paper 42. World Bank.

WALKER, N.J. - SCHULZE, R.E. (2008). Climate change impacts on agro-ecosystem sustainability across three climate regions in the maize belt of South Africa. Agriculture, Ecosystems and Environment. 124, 114-124. http://dx.doi.org/10.1016/j.agee.2007.09.001

WOODWARD, F.I. - THOMPSON, G.B. - MCKEE, I.F. (1991). The effects of elevated concentrations of carbon dioxide on individual plants, populations, communities and ecosystems. Annals of Botany. 67, 2338.

WHEELER, T.R. - BATTS, G.R. - ELLIS, R.H. HADLEY, P. - MORISON, J.I.L. (1996). Growth and yield of winter wheat (Triticum aestivum) crops in response to $\mathrm{CO}_{2}$ and temperature. Journal of Agricultural Science $\quad 127$, 37-48. http://dx.doi.org/10.1017/S0021859600077352 